\title{
SUPRESSÃO DE CORRENTE PARASITA EM ROLAMENTOS DE MOTOR BRUSHLESS DC ACIONADOS POR INVERSOR
}

\author{
ARTIGO ORIGINAL \\ PARIGI FILHO, Éder Aparecido ${ }^{1}$ \\ RIEHL, Rudolf Ribeiro ${ }^{2}$ \\ ULSON, José Alfredo Covolan ${ }^{3}$
}

PARIGI FILHO, Éder Aparecido. RIEHL, Rudolf Ribeiro. ULSON, José Alfredo Covolan. Supressão de corrente parasita em rolamentos de Motor Brushless DC acionados por inversor. Revista Científica Multidisciplinar Núcleo do Conhecimento. Ano 05, Ed. 12, Vol. 04, pp. 42-59. Dezembro de 2020. ISSN: 2448-0959, Link de acesso: https://www.nucleodoconhecimento.com.br/engenharia-eletrica/supressaode-corrente

\footnotetext{
${ }^{1}$ Mestrando em Engenharia Elétrica pela Unesp de Bauru (2017 - 2021). Especialista em Engenharia Elétrica pela Universidade Cândido Mendes (2019). Graduado em Engenharia Elétrica pela Universidade Paulista de Bauru (2013). Técnico em eletrônica pelo Liceu Noroeste de Bauru (2007).

2 Co-orientador. Doutorado (2010) em Engenharia Elétrica pela Faculdade de Engenharia Elétrica e de Computação (FEEC) da Universidade Estadual de Campinas (Unicamp). Mestrado Pela faculdade de Engenharia Elétrica de Bauru (1994). Graduação em Engenharia Elétrica pela Universidade de Bauru (1985).

${ }^{3}$ Orientador. Doutorado em Agronomia (Energia na Agricultura) pela UNESP (2002). Mestrado em Agronomia (Energia na Agricultura) pela UNESP (1997). Possui graduação em Engenharia Elétrica pela Universidade Paulista Julio Mesquita Filho UNESP (1990).
} 


\section{RESUMO}

O acionamento e controle de um motor de corrente contínua sem escovas (Brushless DC motor), é realizado através da utilização de um Inversor de Frequência com Modulação por Largura de Pulso (PWM). Devido à alta frequência deste inversor, capacitâncias parasitas são estabelecidas nas partes metálicas do motor, permitindo a circulação de correntes de alta frequência. Estas correntes que passam pelos rolamentos do motor podem causar erosão eletrostática nas pistas do rolamento, gerando vibrações indesejadas e reduzindo substancialmente a vida útil do mesmo. O objetivo deste trabalho é o estudo de abordagens para a mitigação das correntes parasitas em motores de corrente contínua sem escova, comumente designados de motores BLDC. Mais especificamente, a partir do estudo das abordagens para a mitigação disponíveis na literatura, bem como o estudo e ensaio de um motor BLDC de pequena potência, abordagens para a mitigação da corrente parasita são estudadas levando em consideração suas vantagens e desvantagens num cenário industrial. Através de testes em laboratório, são determinados os valores das suas capacitâncias parasitas, utilizando uma Ponte RLC e, realizados os cálculos destas capacitâncias por meio de equações características, para posterior comparação, permitindo assim a correta especificação de uma nova capacitância interna, de forma a gerar uma alta reatância entre o eixo e carcaça, reduzindo substancialmente os valores das correntes circulantes de modo comum nos rolamento do motor. São apresentados resultados de simulações utilizando as capacitâncias medidas, com e sem a introdução desta nova capacitância entre o eixo e a carcaça do motor, através das curvas da tensão de eixo e corrente de eixo, mostrando que há a mitigação desta corrente de eixo, atendendo as referências citadas no texto. Pode-se concluir que tal abordagem apresenta as seguintes contribuições: mitiga a corrente de descarga nos rolamentos de motores BLDC com grande eficiência; contribui de forma direta para o aumento da vida útil dos motores BLDC; dispensa o uso de abordagens que apresentam a necessidade de manutenção periódica como, por exemplo, as escovas no eixo e/ou graxas condutivas nos rolamentos. Como desvantagem dessa abordagem pode-se citar o aumento de uma etapa no processo de produção do motor. 
Palavras-chave: Supressão de Corrente Parasita, Motor Brushless DC, Corrente de Rolamento, Inversor PWM.

\section{INTRODUÇÃO}

Aplicações industriais que necessitam de velocidade variável empregam sistemas eletrônicos baseados em inversores cuja fonte de tensão emprega modulação por largura de pulso (PWM - Pulse Width Modulation) desde a década de 80. Desde então, os algoritmos de controle trifásico, juntamente com dispositivos com tempos de subida mais rápidos ( $<100 \mathrm{~ns}$ ), vem permitindo maior controle da largura de banda, redução das perdas de comutação do inversor, redução do volume do filtro magnético e ciclos de comutação mais rápidos (4-20 kHz), aspectos esses que impõem redução de harmônicos indesejáveis na corrente do motor, na ondulação no conjugado motor, no ruído acústico e, consequentemente, incremento no desempenho do conjunto acionador (KERKMAN; SKIBINSKI; SCHLEGEL, 2003).

No entanto, todos esses avanços da eletrônica de potência e das técnicas de controle de máquinas elétricas trouxeram novos problemas. Dentre os problemas, pode-se destacar a possibilidade de dano nos rolamentos causados pela circulação de corrente elétrica (corrente parasita) devido a tensão de modo comum (TMC) presente nos modernos sistemas de acionamento eletrônicos, como o inversor PWM. Desta maneira, diversos autores descrevem as relações causa e efeito, permitindo assim o emprego da técnica de mitigação adequada (LINK, 1999), (MÜETZE; BINDER, 2006)).

Nesse cenário, os motores em corrente continua sem escovas, comumente designados por "Brushless DC Motors", cujo acrônimo é BLDC, que também são acionados por inversores PWM, estão sujeitos a correntes parasitas de modo comum nos seus rolamentos e nos rolamentos da carga que acionam, em decorrência do acoplamento capacitivo que surge quando a tensão em modo comum (TMC) é gerada pelo inversor em frequências elevadas. A corrente parasita que passa pelos rolamentos pode causar erosão eletrostática nas pistas do rolamento, gerando 
vibrações indesejadas e reduzindo substancialmente a sua vida útil no motor. $\mathrm{Na}$ Figura 01 pode-se observar o efeito da corrente parasita na pista de um rolamento.

Figura 01 - Rolamento acometido de erosão eletrostática proporcionada pela corrente parasita de modo comum

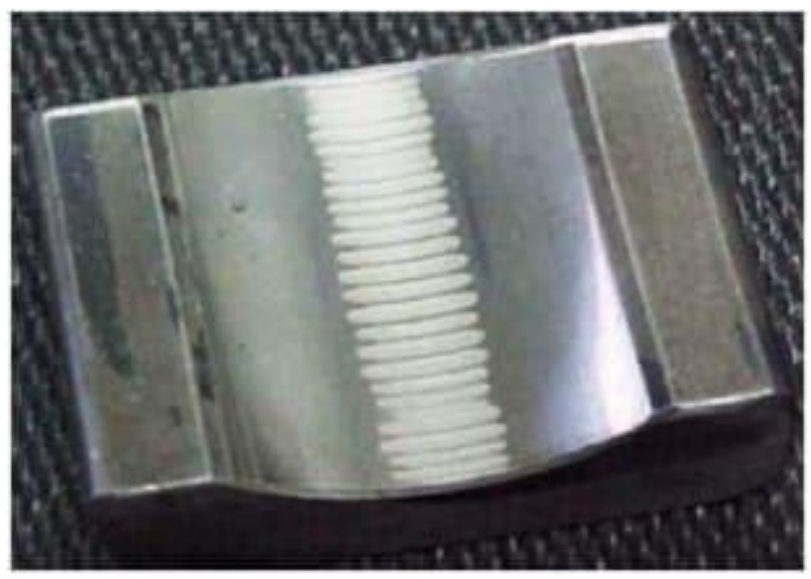

Fonte: RIEHL, Rudolf Ribeiro e RUPPERT, Ernesto, 2012

Diversos são os trabalhos científicos publicados nos últimos anos que buscam entender as causas da tensão no eixo e encontrar soluções para eliminar os danos nos rolamentos. Os rolamentos podem ser protegidos por meio de diversas abordagens (ARAÚJO, 2011). As principais são:

- Isolação dos rolamentos;

- Escovas para aterrar o eixo;

- Blindagem de Faraday nos enrolamentos;

- Graxa condutiva no rolamento;

- Isolamento do eixo do rotor.

Existem diversas abordagens para a supressão (redução) da tensão de eixo em máquinas elétricas, contudo, algumas delas não podem ser empregadas sob certas condições de utilização do motor. Por exemplo, o uso de escovas no eixo da máquina não pode ser empregado em áreas classificadas; a blindagem do rolamento protege o rolamento do motor, mas não necessariamente os das cargas mecânicas. De fato, 
em várias circunstâncias não há opção para a supressão da tensão de eixo em máquinas elétricas rotativas (WILLIAM; WILLWERTH, 2008), Maetani e outro (2011), Adabi e outros (2008).

Nesse contexto, o objetivo deste trabalho é o estudo de abordagens para a mitigação das correntes parasitas em motores de corrente contínua sem escova, comumente designados de motores BLDC. Mais especificamente, a partir do estudo das abordagens para a mitigação disponíveis na literatura, bem como o estudo e ensaio de um motor BLDC de pequena potência, abordagens para a mitigação da corrente parasita são estudadas levando em consideração suas vantagens e desvantagens num cenário industrial.

\section{TENSÃO NO EIXO DE UM MOTOR BLDC}

O estudo da circulação de correntes parasitas em um motor BLDC tem como ponto de partida o circuito equivalente de alta frequência de motor de indução trifásico que pode ser visto na figura 02. Nesse circuito, os parâmetros distribuídos $R, L$ e $C$ representam o acoplamento de altas frequências entre os enrolamentos do estator $e$ do rotor. Desta forma, Zrc é a impedância entre o rotor e a carcaça do motor, também chamada de impedância de entreferro Zg; Zer é a impedância entre os enrolamentos do estator e o rotor, Zec é a impedância entre os enrolamentos do estator e a carcaça, e Zb a impedância entre o rotor e os rolamentos. $R w$ e $L w$ representam a impedância equivalente do condutor por onde circula a corrente de rolamento e $R g$ a resistência do condutor conectado entre a carcaça e a terra (RIEHL; RUPPERT, 2012). 
Figura 02 - Circuito equivalente de alta frequência de um motor de indução

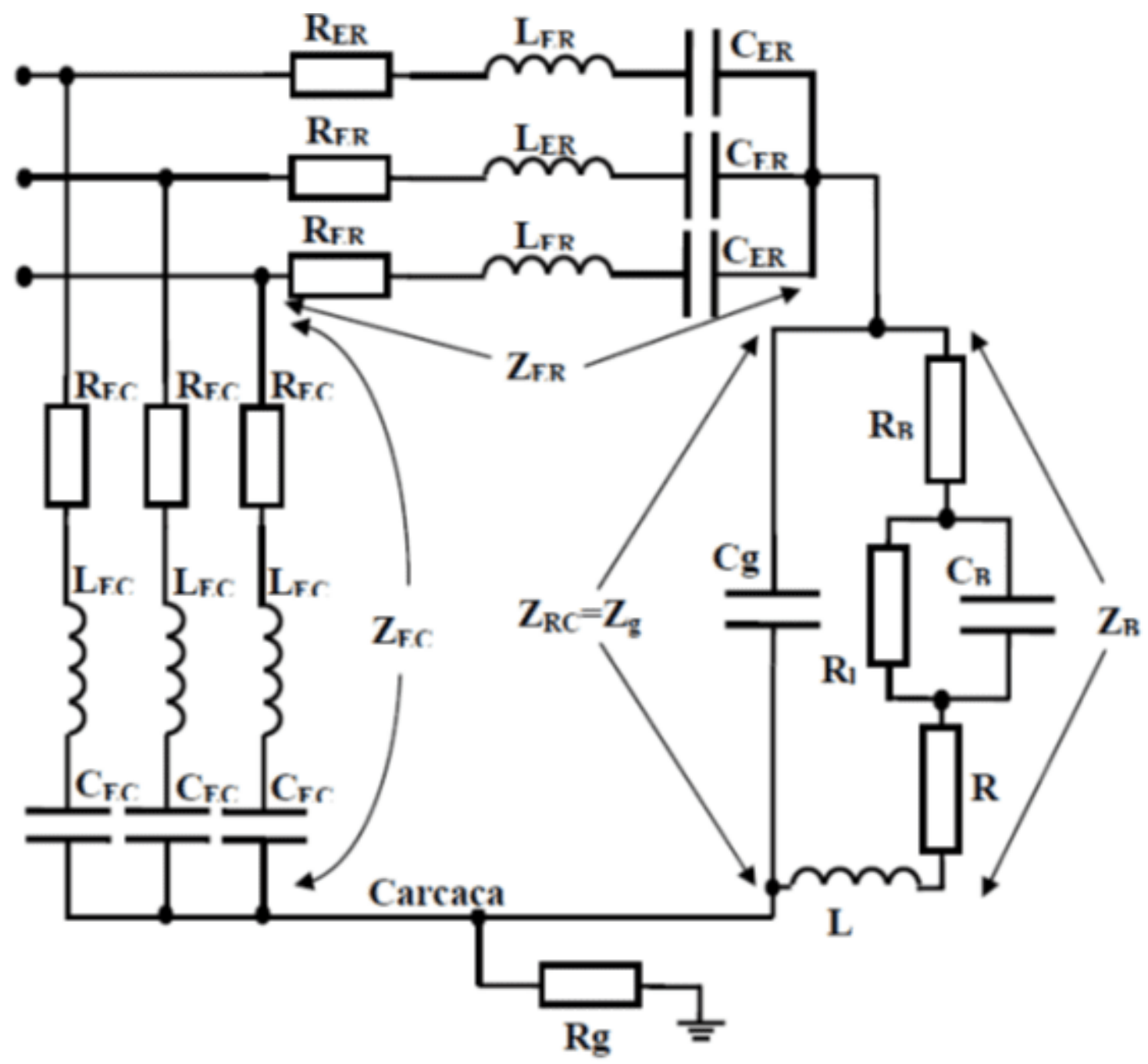

Fonte: RIEHL, Rudolf Ribeiro e RUPPERT, Ernesto, 2012

Pode-se simplificar o circuito da figura 02 impondo-se a condição de que em frequências da ordem de 4 e $20 \mathrm{kHz}$, que são típicas frequências de chaveamento de inversor PWM, as impedâncias parasitas do motor, têm característica puramente capacitiva (RIEHL; RUPPERT, 2012). Assim, o circuito equivalente da figura 02 pode ser representado somente por meio das capacitâncias parasitas de altas frequências, conforme mostrado na figura 03 . 
Figura 03 - Circuito equivalente de alta frequência simplificado de um motor de indução

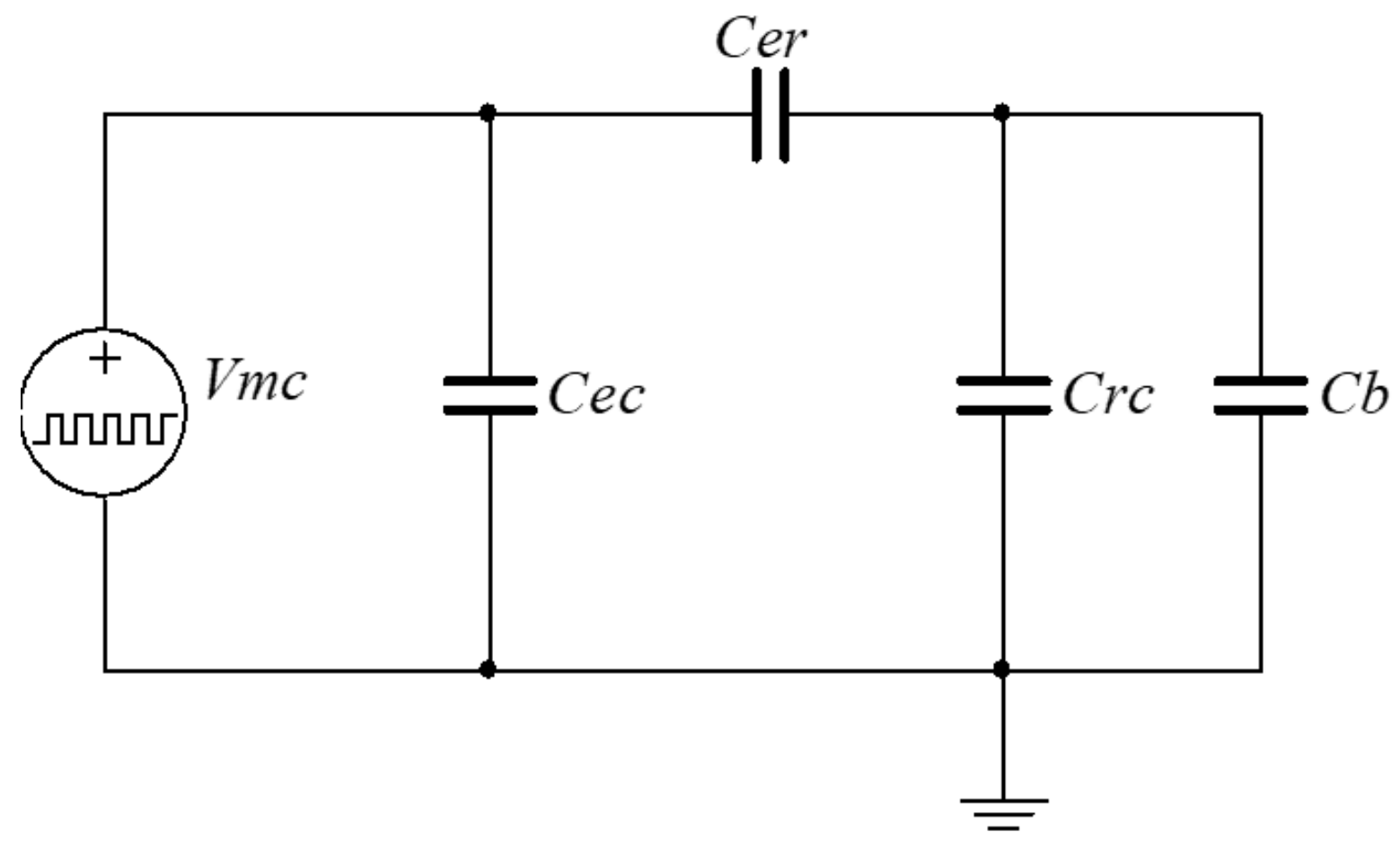

Fonte: RIEHL, Rudolf Ribeiro e RUPPERT, Ernesto, 2012

$\mathrm{Na}$ figura 03, Vmc é a tensão de modo comum, $\mathrm{Cec}$ é a capacitância entre os enrolamentos estatóricos e a carcaça do motor, Cer é a capacitância entre os enrolamentos do estator e do rotor, Crc é a capacitância entre o rotor e a carcaça e $C b$ é a capacitância do rolamento do mancal. Desta forma, a partir do circuito da figura 03 pode-se estabelecer a circulação de correntes elétricas de modo comum, também chamada de correntes parasitas conforme mostrado na figura 04 . 
Figura 04 - Correntes circulantes no motor

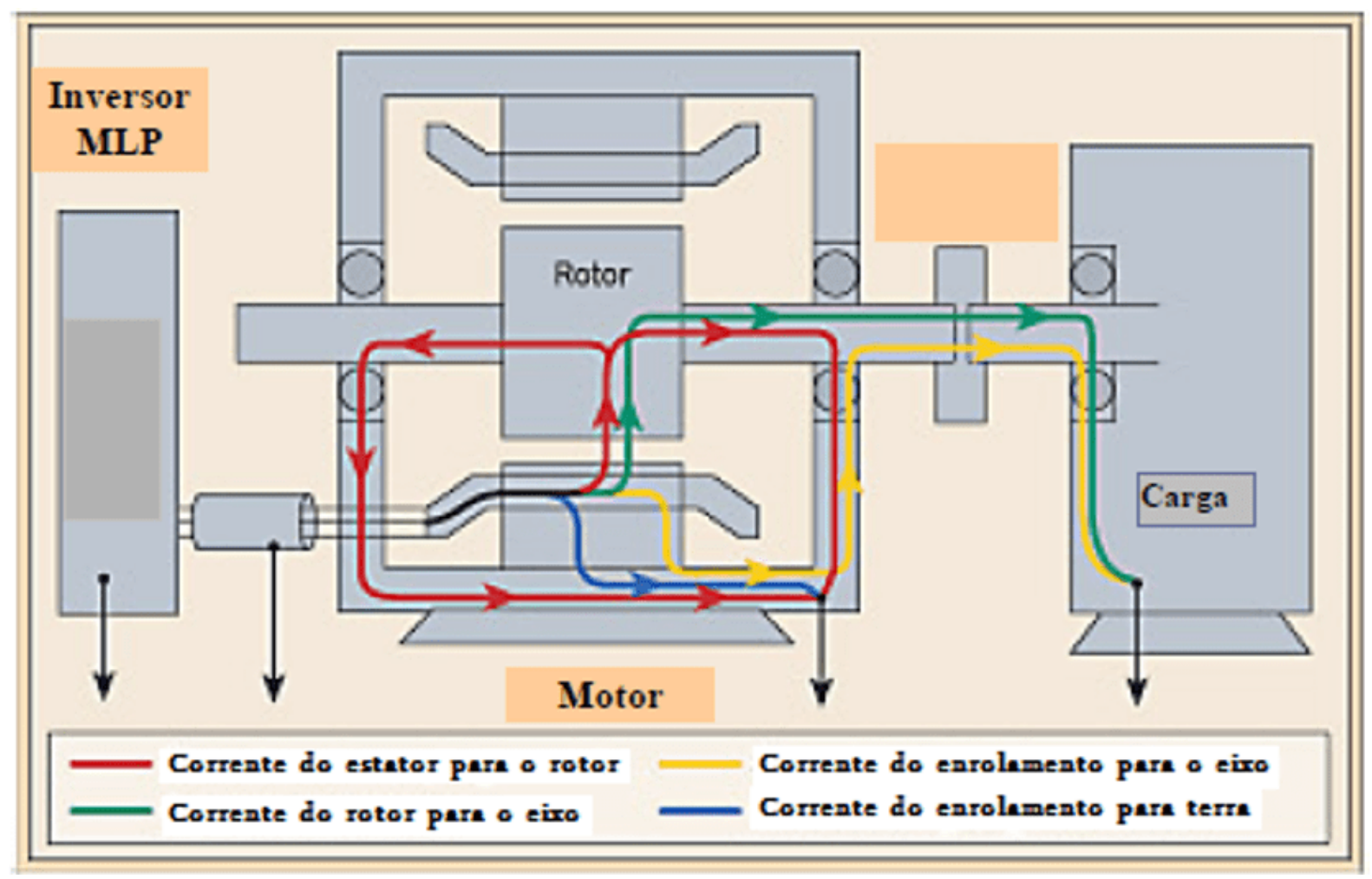

Fonte: Adaptado de RIEHL, Rudolf Ribeiro e RUPPERT, Ernesto, 2012

Em particular, nos motores BLDC, em que há na superfície do rotor, imãs fixados por meio de um adesivo apropriado para trabalhar em altas velocidades, é estabelecida uma capacitância na periferia do rotor definida por Cr. Nesse contexto, a figura 03 pode ser a adaptada conforme mostra a figura 05. 
Figura 05 - Circuito equivalente de alta frequência de um servo motor BLDC

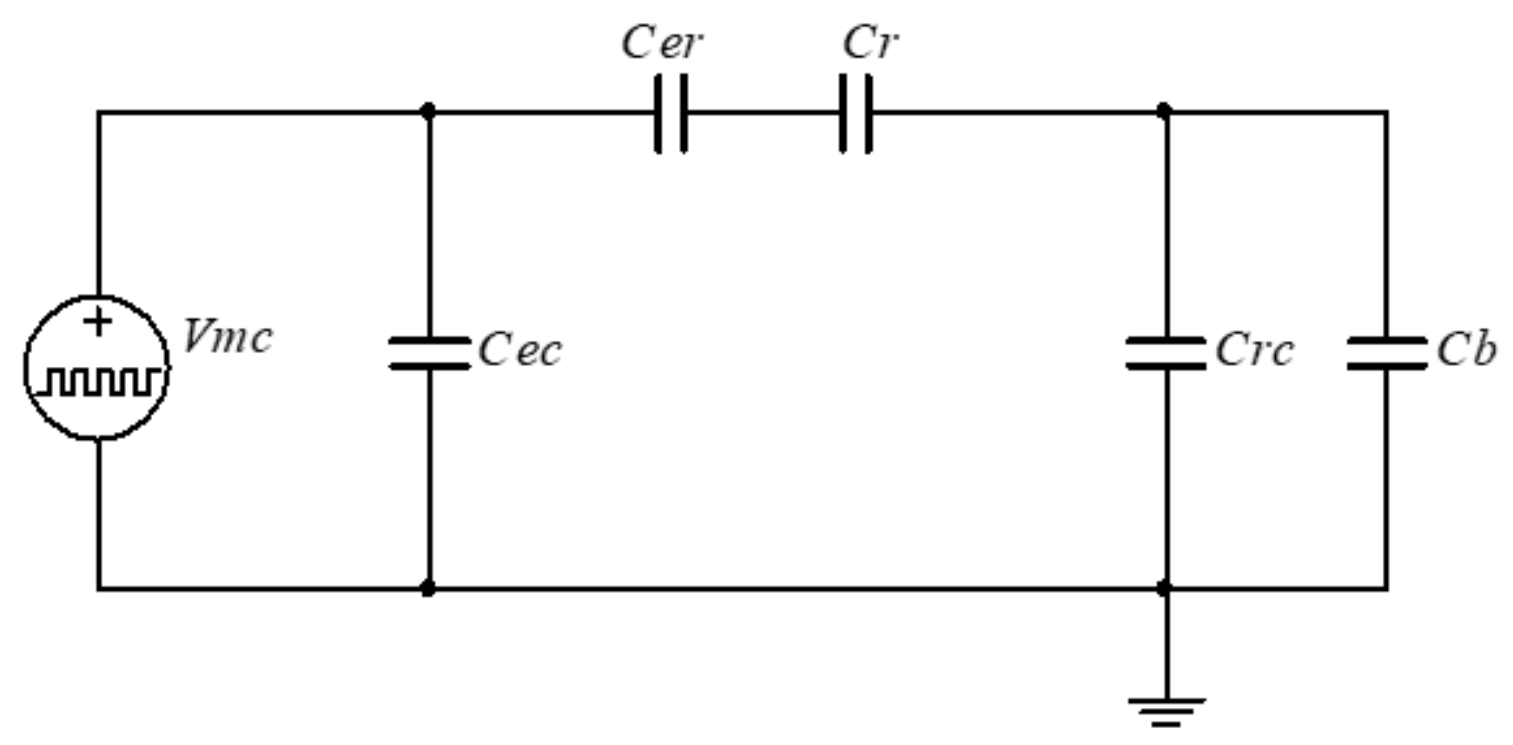

Fonte: Autor

Portanto, por meio de inspeção da figura 05 , a tensão de eixo $\left(V_{s h}\right)$ é resultante de um divisor de tensão, podendo ser determinada pela equação 01 .

$$
V_{s h}=\frac{C e r+C r}{C e r+C r+C r c+C b} \cdot V_{m c}
$$

A relação entre $V_{s h}$ e $V m c$ é conhecida como relação de tensão de rolamento (BVR) e fornece informações importantes sobre o fenômeno de carga e descarga no rolamento, como por exemplo, a tensão de ruptura $\left(V_{\text {rup }}\right)$ para o respectivo valor da espessura da película lubrificante no rolamento abaixo da qual a ruptura dielétrica não ocorre segundo Busse e outro (1997).

A figura 06 ilustra a as principais capacitâncias concentradas ao longo da estrutura de um motor cuja caraça é metálica. 
Figura 06 - Estrutura do motor com suas capacitâncias

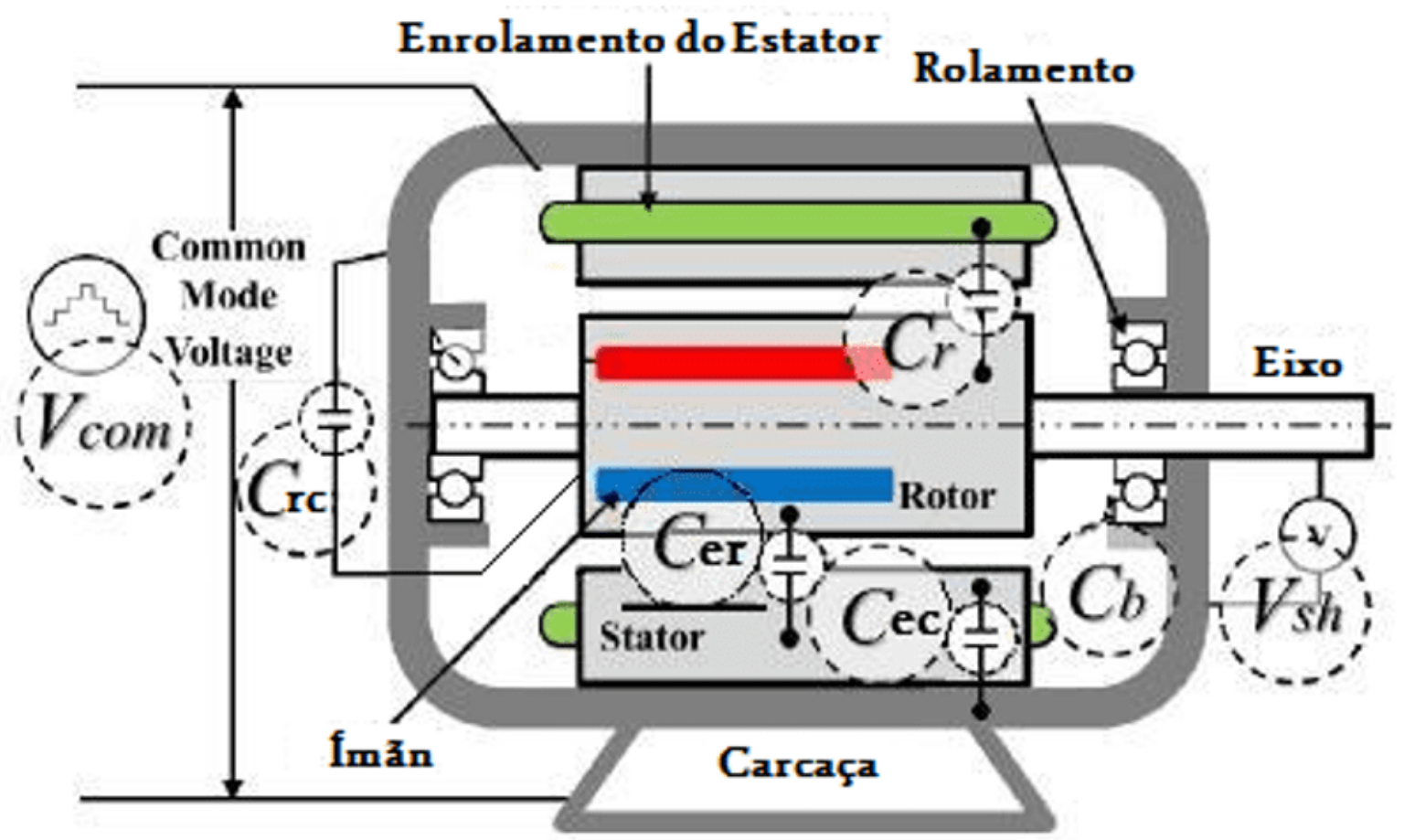

Fonte: Adaptado de KIM, Kyung Tae e Hur, Jin, 2013

\section{IDENTIFICAÇÃO DAS CAPACITÂNCIAS}

A identificação das capacitâncias para o circuito da figura 05 pode ser feita por expressões com base na teoria eletromagnética ou, por meio de medições realizadas em laboratório. Segundo (WILLIAM; WILLWERTH, 2008), (JOUANNE; ZHANG, 1999) e (MUETZE; BINDER, 2007) é possível determinar as capacitâncias de forma aproximada empregando as equações 02 a 06, cujas definições dos parâmetros e variáveis estão mostradas na Tabela 01. 


$$
\begin{gathered}
\text { Cec }=\frac{K_{e c} \cdot N_{s} \cdot \varepsilon_{r i s o l} \cdot \varepsilon_{0} \cdot\left(W_{d}+2 * W_{s}\right) \cdot L_{s}}{e s p} \\
C e r=\frac{K_{r c} \cdot \varepsilon_{0} \cdot \varepsilon_{r i s o l} \cdot N_{s} \cdot A b_{r} \cdot L_{r}}{g a p} \\
C r=\frac{\varepsilon_{0} \cdot \pi \cdot N_{m} \cdot L_{m} \cdot L_{r}}{R_{m}} \\
C r c=\frac{K_{r c} \cdot \varepsilon_{0} \cdot \varepsilon_{r a r} \cdot \pi \cdot L_{r}}{\ln \frac{R_{s}}{R_{r}}} \\
C b=\frac{\varepsilon_{0} \cdot \varepsilon_{r l} \cdot 4 \pi \cdot N_{b b}}{\frac{1}{r_{b b}}-\frac{1}{r_{b b}+d_{l}}}
\end{gathered}
$$

De maneira a identificar as capacitâncias e aferi-las com medições feitas em laboratório, foi empregado um motor BLDC com potência de $0,75 \mathrm{~kW}$, modelo GK6040, fabricado pela Golden-age Motores Tecnologia Corp. Ltda. para o estudo de caso. O Motor foi acionado por um inversor PWM com frequência de chaveamento de $10 \mathrm{kHz}$ do fabricante Motoppar Indústria e Comércio de Automatizadores Ltda. Na figura 07 tem-se a vista explodia do referido motor com a indicação dos principais componentes. Na tabela 01 são apresentados os parâmetros elétricos e mecânicos do motor para o emprego das equações de 02 a 06. 
Figura 07: Vista explodida do motor BLDC modelo GK6040

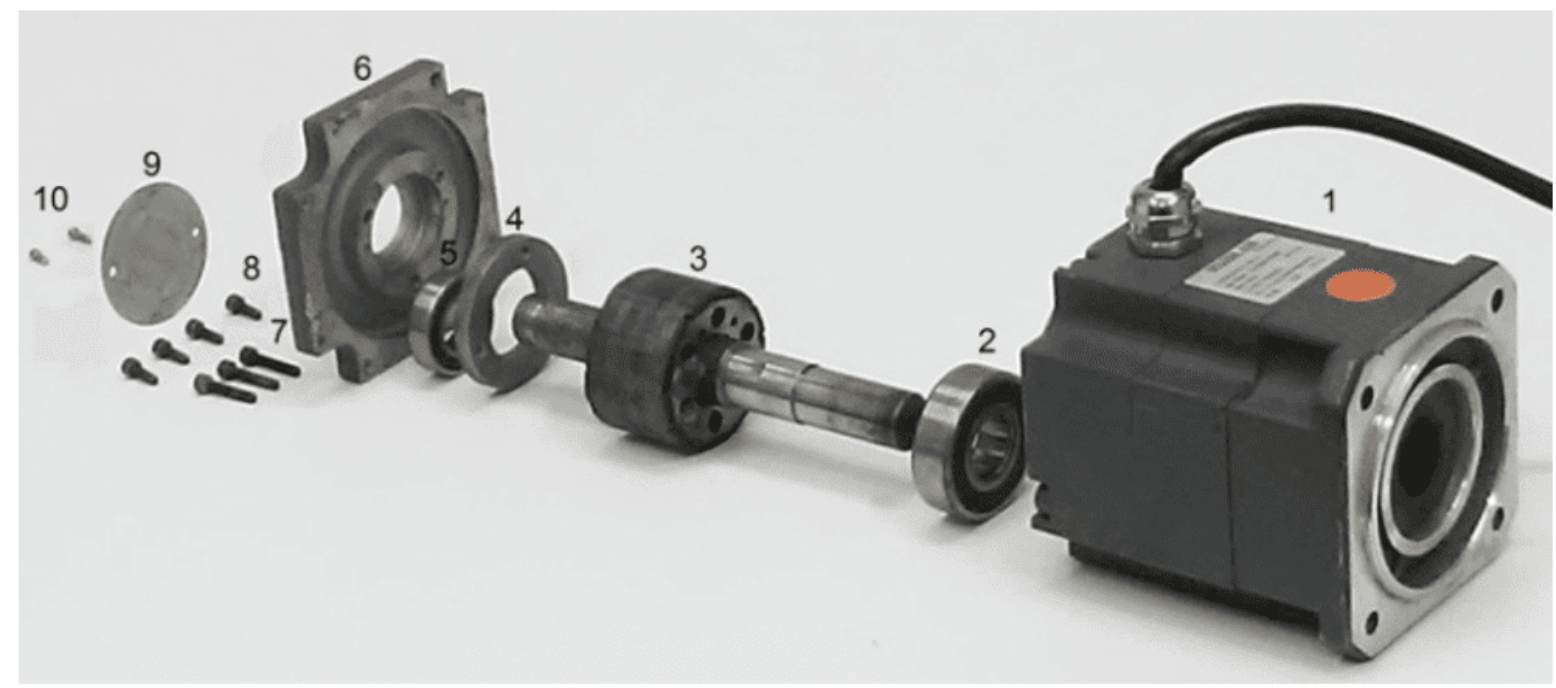

Legenda: 1) Estator, 2) Rolamento frontal, 3) Rotor, 4) Anel de fixação, 5) Rolamento traseiro, 6) Tampa traseira, 7) Parafusos do bloco, 8) Parafusos da tampa, 9) Tampa de inspeção, 10) Parafusos da tampa de inspeção. Fonte: Autor

Por meio das equações de 02 a 06 é possível determinar as capacitâncias parasitas, entretanto, tais expressões matemáticas não levam em consideração todos os aspectos geométricos do motor, como o espraiamento de campo elétrico, e outros fenômenos. Assim, visando maior exatidão na identificação das capacitâncias parasitas, medições das capacitâncias foram realizadas empregando o método do gerador de sinais (HP 33120aㅡ) e osciloscópio digital (Tektronix TDS 1001) na frequência de $10 \mathrm{kHz}$.

TABELA 01: Parâmetros elétricos e mecânicos do BLDC modelo GK6040.

\begin{tabular}{|l|l|l|}
\hline Parâmetro & Valor & Unidade \\
\hline Permissividade do vácuo & $8,85 \times 10^{-12}$ & $\mathrm{~F} / \mathrm{m}$ \\
\hline Permissividade relativa do ar & 1,0004 & \\
\hline Permissividade relativa do isolante & 2,1 & \\
\hline Permissividade relativa do lubrificante & 2,6 & \\
\hline
\end{tabular}

Disponível em: https://www.nucleodoconhecimento.com.br/engenharia-eletrica/supressao-decorrente 


\begin{tabular}{|c|c|c|c|}
\hline Rs & Raio do estator & 27,3 & {$[\mathrm{~mm}]$} \\
\hline$R r$ & Raio do rotor & 26,6 & {$[\mathrm{~mm}]$} \\
\hline$W_{I}$ & Largura da ranhura do estator & 5,1 & {$[\mathrm{~mm}]$} \\
\hline$W_{h}$ & Altura da ranhura do estator & 6,0 & {$[\mathrm{~mm}]$} \\
\hline Ls & Comprimento da ranhura do estator & 38,0 & {$[\mathrm{~mm}]$} \\
\hline$L r$ & Comprimento da ranhura do rotor & 33,0 & {$[\mathrm{~mm}]$} \\
\hline esp & Espessura do isolante da ranhura & 0,30 & {$[\mathrm{~mm}]$} \\
\hline Ns & Número de ranhuras do estator & 18 & {$[\mathrm{~mm}]$} \\
\hline gap & Espessura do entreferro & 0,70 & {$[\mathrm{~mm}]$} \\
\hline$L_{m}$ & Largura do imã do rotor & 11,1 & {$[\mathrm{~mm}]$} \\
\hline$E_{m}$ & Espessura do imã do rotor & 2,80 & {$[\mathrm{~mm}]$} \\
\hline$N_{m}$ & Número de imãs do rotor & 13 & \\
\hline Kec & Fator de empilhamento do estator & 1,0 & \\
\hline Krc & Fator de empilhamento do rotor & 1,0 & \\
\hline$N_{b b 1}$ & Número de esferas do rolamento 6204 2rs & 08 & \\
\hline$r_{b b 1}$ & Raio da esfera do rolamento 6204 2rs & 4,0 & {$[\mathrm{~mm}]$} \\
\hline$d_{11}$ & Espessura de lubrificante rolamento 6204 2rs & 15 & {$[\mu \mathrm{m}]$} \\
\hline$N_{b b 2}$ & Número de esferas do rolamento 6300 2rs & 08 & \\
\hline$r_{b b 2}$ & Raio da esfera do rolamento 6300 2rs & 2,0 & {$[\mathrm{~mm}]$} \\
\hline$d_{12}$ & Espessura de lubrificante rolamento 6300 2rs & 05 & {$[\mu \mathrm{m}]$} \\
\hline
\end{tabular}

Fonte: Autor

A Tabela 02 apresenta os valores das capacitâncias calculadas e medidas.

TABELA 02: Capacitâncias parasitas calculadas e medidas do BLDC em estudo.

\begin{tabular}{|l|l|l|}
\hline Capacitância & Calculada & Medida \\
\hline Cec & 678,3 pF & $682 \mathrm{pF}$ \\
\hline Cer & $55,22 \mathrm{pF}$ & $75 \mathrm{pF}$ \\
\hline Cr & $168,6 \mathrm{pF}$ & $201 \mathrm{pF}$ \\
\hline
\end{tabular}

Disponível em: https://www.nucleodoconhecimento.com.br/engenharia-eletrica/supressao-decorrente 


\begin{tabular}{|l|l|l|}
\hline Crc & $70,67 \mathrm{pF}$ & $76 \mathrm{pF}$ \\
\hline Cb1 & $2,47 \mathrm{nF}$ & $0,30 \ldots 2,85 \mathrm{nF}$ \\
\hline Cb2 & $1,85 \mathrm{nF}$ & $0,40 \ldots 2,10 \mathrm{nF}$ \\
\hline
\end{tabular}

Fonte: Autor

As discrepâncias entre os valores calculados e medidos decorrem das hipóteses simplificadoras impostas na dedução das expressões e imprecisões nas medidas dimensionais do motor. Como exemplo pode-se citar o espraiamento de campo e a capacitância da cabeça das bobinas estatóricas que não são contempladas pelas expressões de 02 a 06.

\section{PROPRIEDADES ELÉTRICAS DE UM ROLAMENTO}

As propriedades elétricas do rolamento têm grande influência no comportamento das correntes parasitas e são muito complexas, devido às alterações aleatórias de sua condutividade, que podem variar de boa à péssima, dependendo da velocidade do eixo, carga do rolamento, temperatura e viscosidade da graxa lubrificante, fatos que explicam a grande faixa de valores obtidos nas medições segundo Busse e outros (1997). De acordo com essa variação de condutividade, as correntes que fluem pelos rolamentos podem ser classificadas em dois modos distintos:

a) Condução ou $d v / d t$;

b) Descarga ou EDM (Electric Discharge Machining).

Cabe ressaltar que esses modos da corrente de rolamento podem ocorrer simultaneamente ou não.

A corrente de condução ou de $d v / d t$ é caracterizada por fluir pelos rolamentos, sempre em sincronismo com as variações da tensão $V m c$, ocorrendo independentemente da velocidade do eixo do motor. Esta corrente se origina do acoplamento do enrolamento 
trifásico para o núcleo do rotor, através das capacitâncias $\operatorname{Cer} e \mathrm{Cr}$, que são as responsáveis pelo estabelecimento da tensão de eixo.

O fenômeno da corrente de descarga no rolamento é relacionado à ruptura dielétrica da graxa de lubrificação, que pode suportar valores de tensões inferiores ao valor limite da tensão de ruptura Vrup, considerando-se um conjunto específico de condições de operação do motor, tais como temperatura, carga e velocidade do eixo (BINDER; MUETZE, 2008). A existência de um curto-circuito intermitente ou aleatório das capacitâncias Cb1 e/ou Cb2 é caracterizada por sua ocorrência repentina, independentemente das bordas de transição da tensão $V m c$, sendo relacionada, simplesmente, ao período de maior amplitude da tensão $V m c$, bem como ao nível de carregamento do eixo (MUETZE; BIDER, 2007). Assim, a ocorrência destes curtoscircuitos leva ao surgimento da corrente de descarga que degrada o rolamento com o efeito visualizado na figura 01 .

O modelo elétrico mais aprimorado do rolamento é representado por uma resistência denominada $R b$ de 10 ohms, a qual se encontra conectada em série com a capacitância Cb e uma impedância não-linear, denominada Znl (figura 08) (MUETZE; BIDER, 2007). Essa impedância é ligada em paralelo com a capacitância $C b$, com a finalidade de simular a variação instantânea da impedância do rolamento.

Esta impedância passa da característica capacitiva para resistiva, repentinamente, quando ocorre uma ruptura dielétrica da película de lubrificação, descarregando instantaneamente, a energia armazenada no capacitor $\mathrm{Cb}$ do rolamento. Portanto, a impedância $Z n l$ descreve o comportamento não-linear que retrata as descargas elétricas parciais entre pistas e esferas nas modelagens dos rolamentos. No momento da ruptura dielétrica, a impedância do rolamento é reduzida a um simples valor ôhmico de resistência $(R b)$, cujo efeito se iguala ao de um contato quase-metálico entre as superfícies das esferas e pistas (BINDER; MUETZE, 2008). 
Figura 08 - Circuito elétrico simplificado do rolamento de um motor

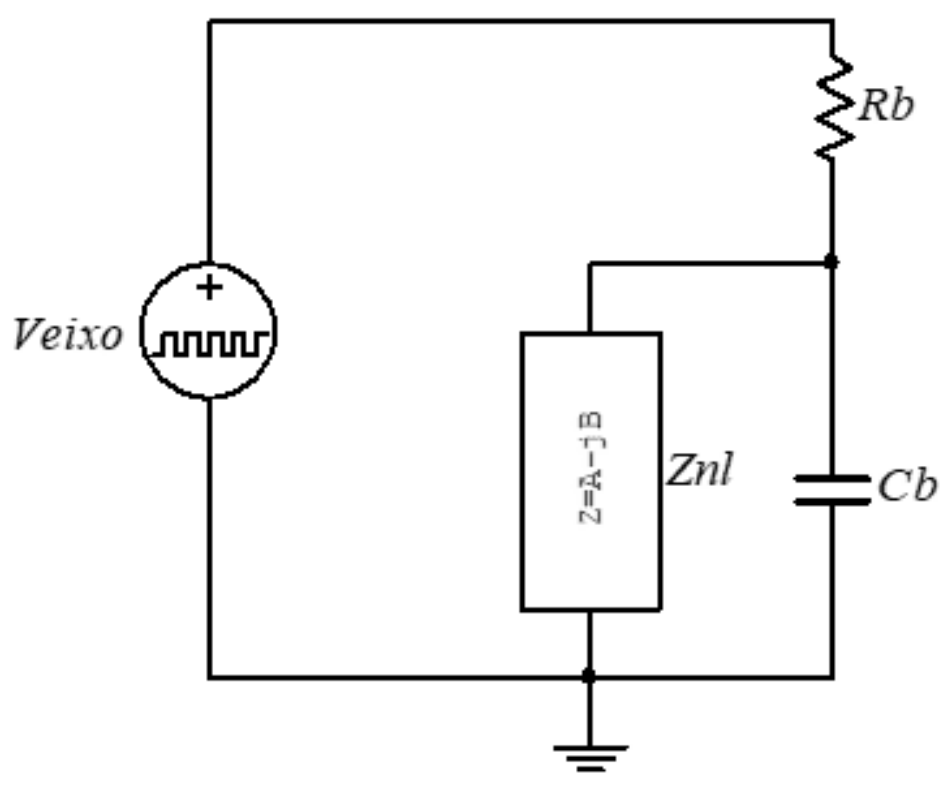

Fonte: Autor

\section{VALIDAÇÃO DO CIRCUITO EQUIVALENTE E CORRENTE DE DESCARGA NOS ROLAMENTOS}

De posse das capacitâncias parasitas da Tabela 02, pode-se parametrizar o circuito da figura 05 modificado pelo circuito elétrico equivalente do rolamento (figura 08) e assim tem-se o circuito equivalente da figura 09. Neste circuito, a impedância não linear $Z n l$ foi substituída por uma chave para simular uma disrrupção através do rolamento. A fim de verificar a validade do circuito da figura 09 , simulações foram realizadas utilizando o software MultiSim da National Instruments e os resultados são mostrados na figura 10. Nota-se boa conformidade na tensão de eixo com o valor medido e apresentado na figura 11. 
Figura 09 - Circuito equivalente de alta frequência para o servomotor BLDC modelo GK6040

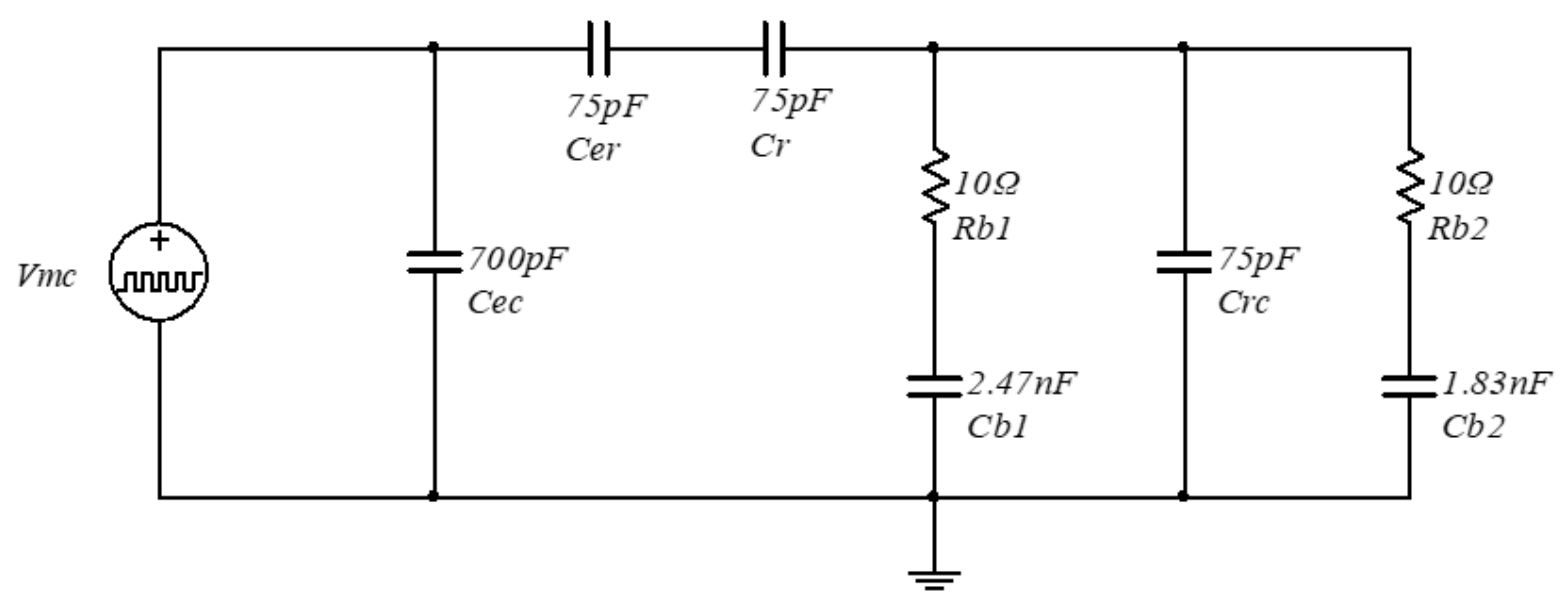

Fonte: Autor

Figura 10 - Simulação a partir da figura 09 da tensão de modo comum $\left(V_{m c}\right)$ e da tensão de eixo $\left(V_{s h}\right)$

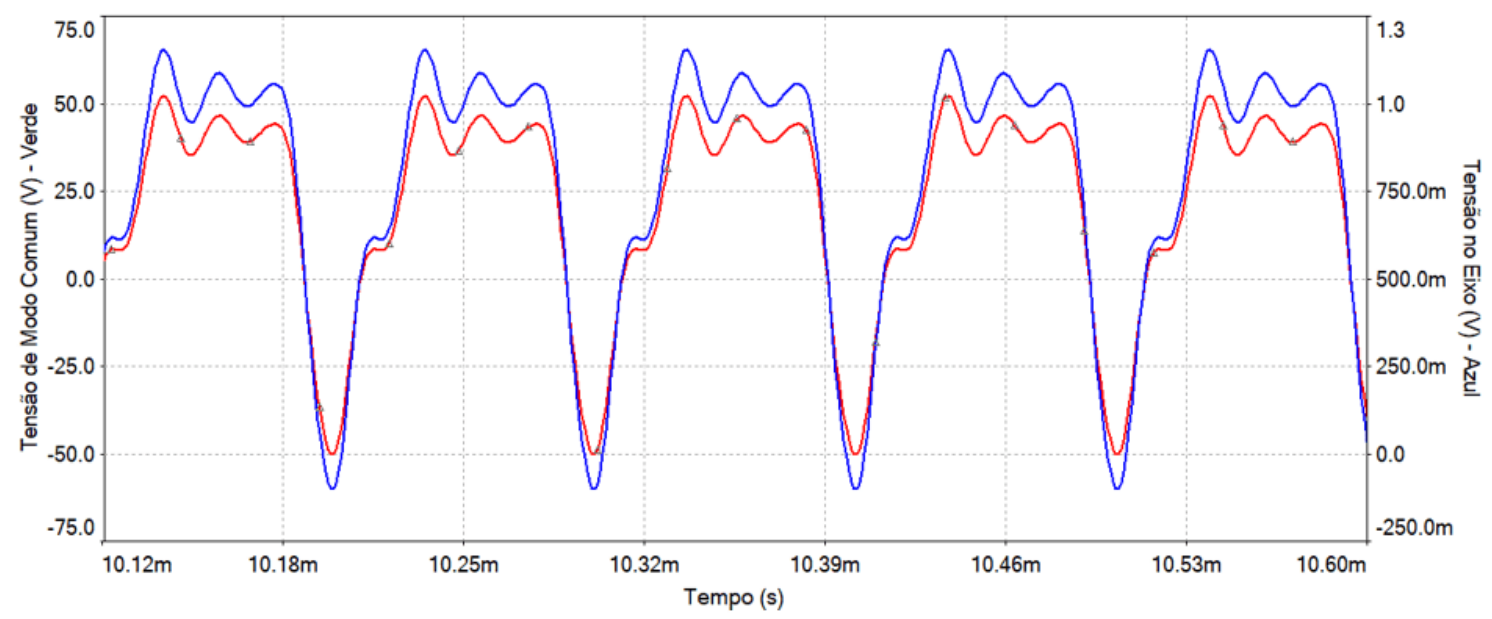

Fonte: Autor

RC: 68583

Disponível em: https://www.nucleodoconhecimento.com.br/engenharia-eletrica/supressao-decorrente 
Figura 11: Tensão de modo comum $(V m c)$ e tensão de eixo (Veixo) com o motor não aterrado

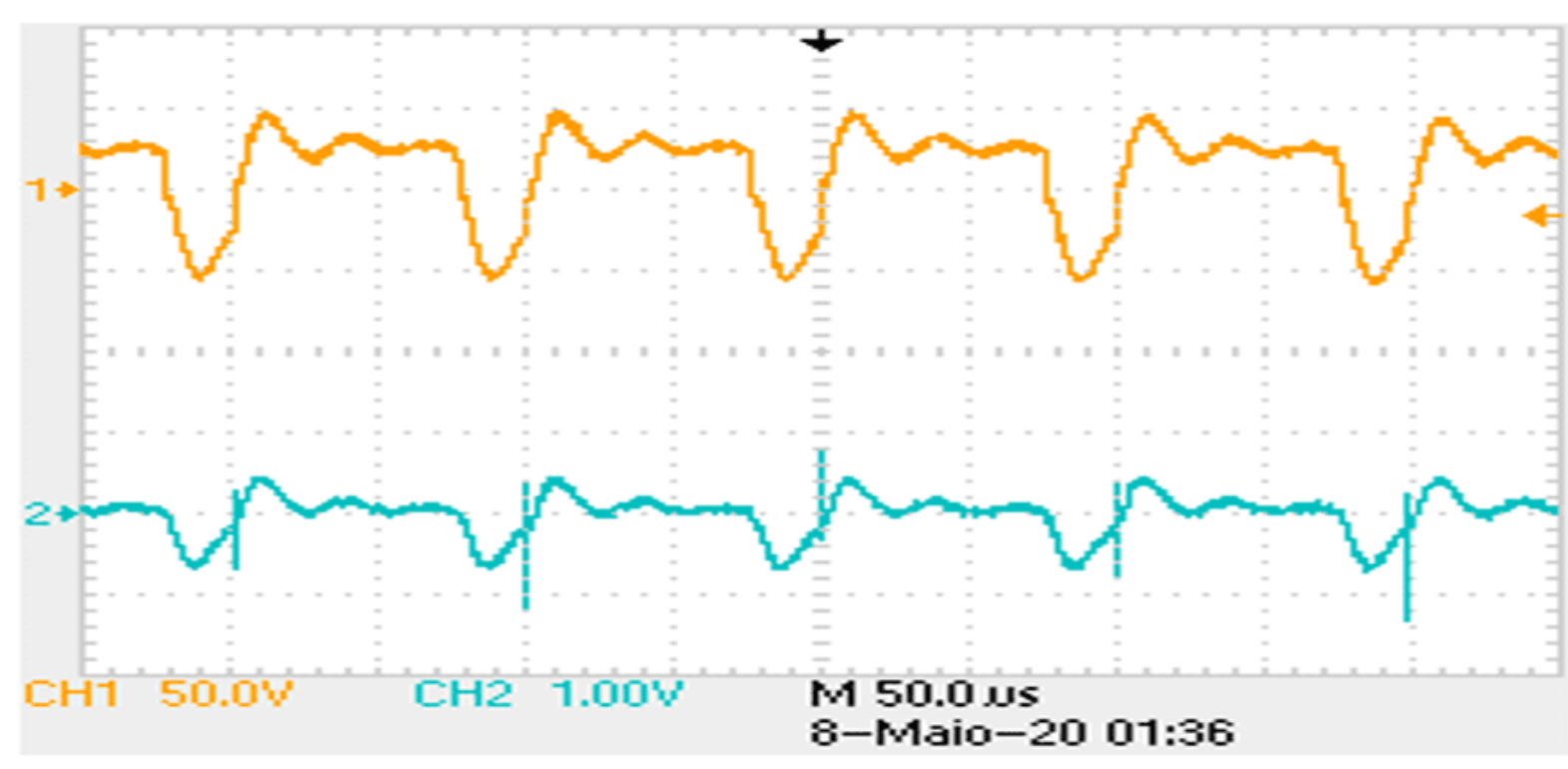

Fonte: Autor

A tensão entre o eixo e carcaça, que representa a tensão sobre os rolamentos, mostrada na figura 10, apresenta valores da ordem de até 1,0 $\mathrm{V}_{\mathrm{pp}}$, bem superior aos $350 \mathrm{~m}$ VPP recomendados em (SIEMENS A\&D SD CS SERVICE COOPERATION, 2006), para que não ocorra deterioração dos rolamentos.

Os resultados das simulações indicam que as correntes de condução ocorrem assimetricamente nos rolamentos, devido à diferença entre os valores das capacitâncias existente nos rolamentos $\left(C_{b 1}=2,47 \mathrm{nF}\right.$ e $\left.C_{b 2}=1,83 \mathrm{nF}\right)$. Nas figuras 12 e 13 são mostradas as formas de onda da corrente de condução e de descarga (EDM) que fluem nos rolamentos. No rolamento 62042 rs tem-se a corrente de condução da ordem de $2,5 \mathrm{~mA}$ (pico) e a corrente de descarga com pico da ordem de $35 \mathrm{~mA}$, e no rolamento 63002 rs tem-se a corrente de condução da ordem de 2,3mA (pico) e a corrente de descarga com pico da ordem de $25 \mathrm{~mA}$. 
Figura 12 - Corrente (vermelho) no rolamento de 6204 2rs e tensão no eixo (verde). 0 transitório indica uma corrente de descarga

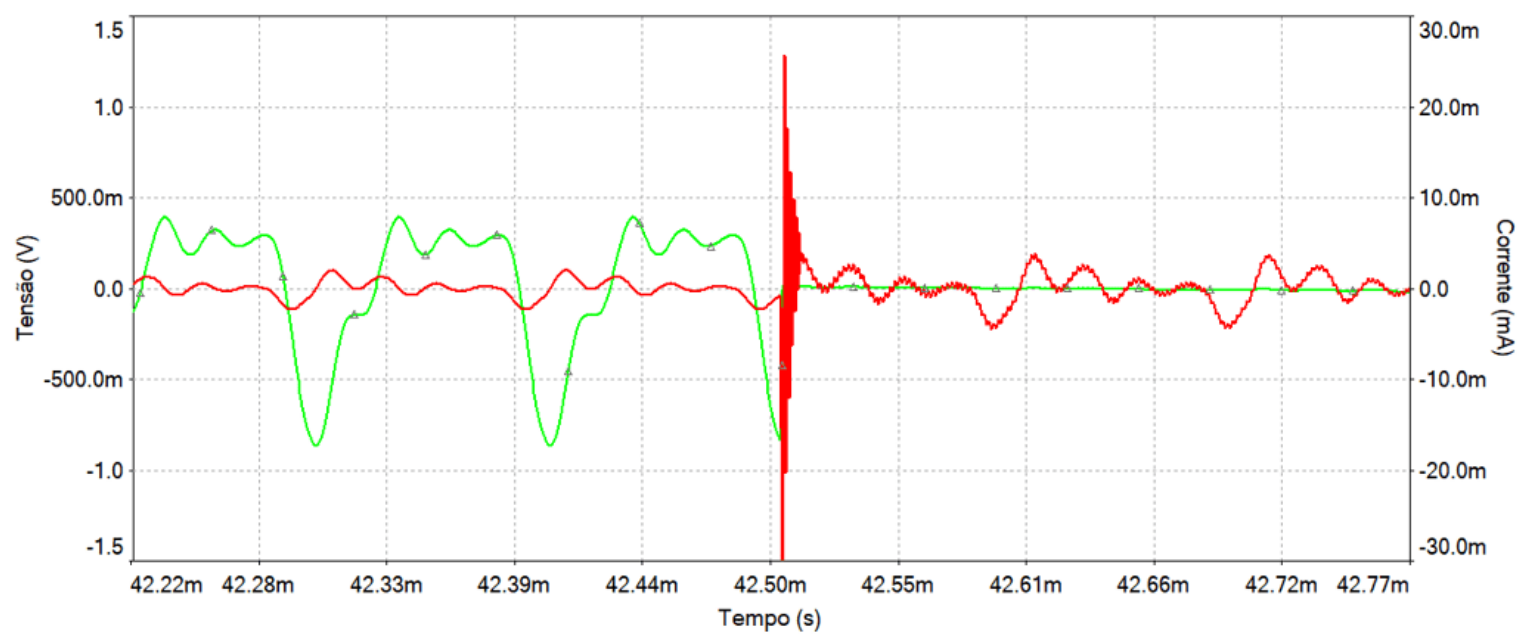

Fonte: Autor

Figura 13 - Corrente (vermelho) no rolamento de 6300 2rs e tensão no eixo (verde). 0 transitório indica uma corrente de descarga

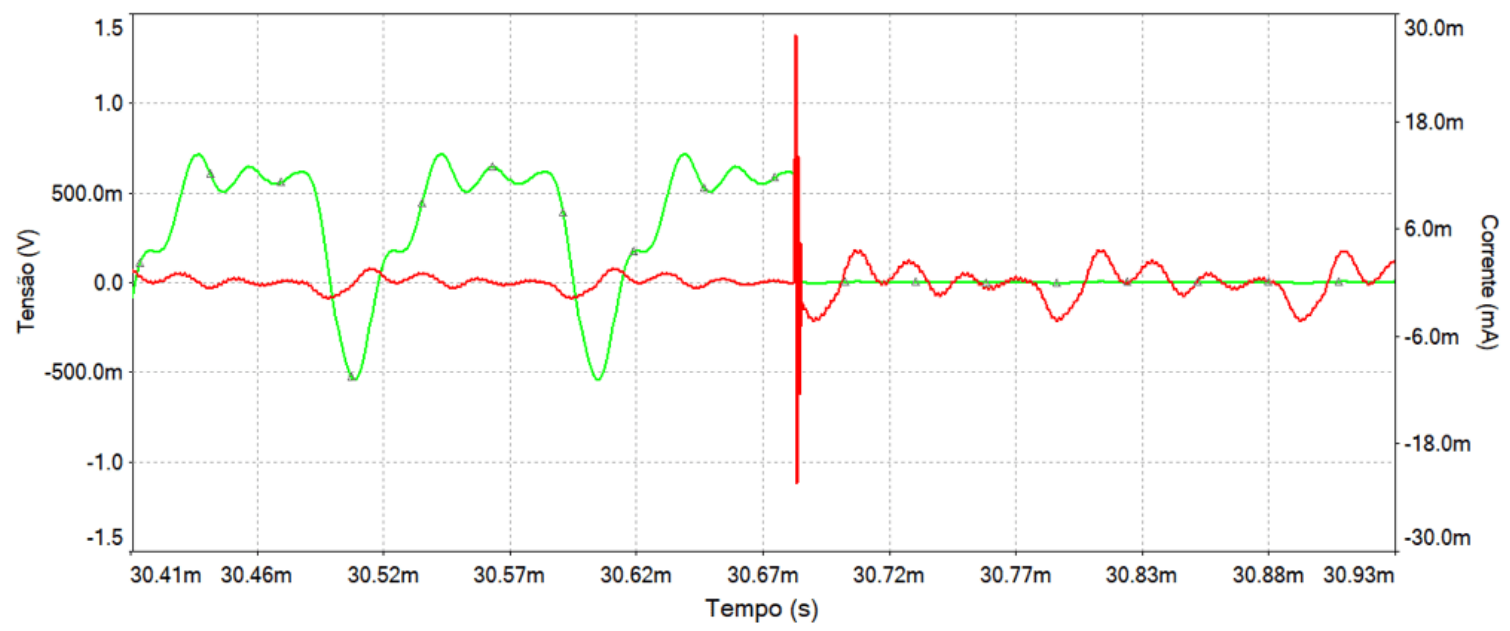

Fonte: Autor

RC: 68583

Disponível em: https://www.nucleodoconhecimento.com.br/engenharia-eletrica/supressao-decorrente 


\section{AVALIAÇÃO DAS ABORDAGENS DE SUPRESSÃO DA CORRENTE PARASITA NOS ROLAMENTOS EM MOTORES BLDC}

A fim de reduzir a tensão entre o eixo e carcaça e assim mitigar a corrente de descarga, diversas abordagens foram propostas por diversos pesquisadores e são apresentadas na sessão I. O uso de escovas no eixo com a finalidade de curto circuitar a tensão de eixo com a carcaça ou, inserir capacitores em paralelo com as capacitâncias parasitas entre o eixo-carcaça é factível em motores de potência elevada cuja manutenção é facilitada. Entretanto, em motores BLDC, além de serem de pequena dimensão, foram concebidos para não terem manutenção periódica frequente e, portanto, o uso de escovas não é a prática adotada. A blindagem dos enrolamentos estatóricos apresenta bom desempenho na mitigação da tensão de eixo, contudo seu custo é proibitivo em se tratando de motores comerciais (ARAÚJO, 2011). O emprego de graxa condutiva tem a desvantagem de com o passar de tempo sua eficiência ficar comprometida pelas impurezas decorrentes do desgaste do rolamento. $\mathrm{O}$ isolamento dos rolamentos resolve o problema da deterioração dos rolamentos do motor, mas não garante que não ocorram danos aos rolamentos das cargas mecânicas acopladas ao eixo do motor BLDC (ARAÚJO, 2011).

Nesse cenário, em Maetani e outro (2015) tem-se a proposta da criação de uma capacitância no rotor, entre o eixo e o núcleo do rotor com a finalidade de gerar uma reatância capacitiva de alto valor e assim reduzir a tensão entre eixo e carcaça a

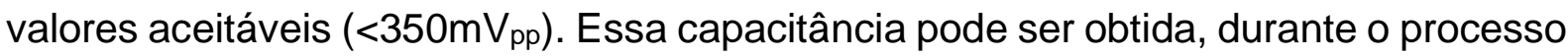
de fabricação, por meio da deposição de uma película dielétrica entre o rotor e o eixo. Do ponto de vista do circuito equivalente, essa capacitância $\left(C_{d}\right)$ aparece em série com a capacitância do rotor e impõe a redução da tensão de eixo. Na figura 14 temse o circuito equivalente em alta frequência, com a capacitância $C_{d}$. 
Figura 14 - Circuito equivalente de alta frequência para o motor BLDC com a capacitância eixo-rotor $\left(C_{d}\right)$

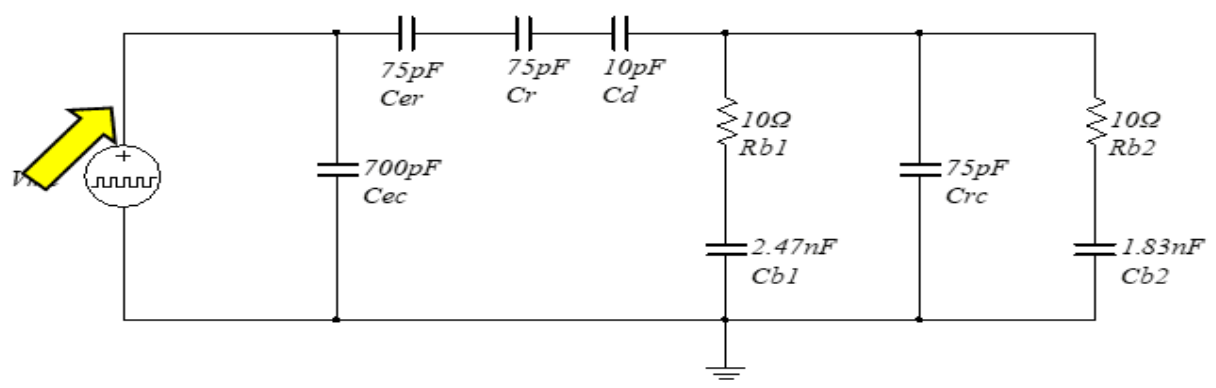

Fonte: Autor

No motor em questão, a capacitância $C d$ tem que ser menor que $22 \mathrm{pF}$ para que a tensão de eixo seja inferior a 350mVpp recomendados em (BINDER; MUETZE, 2008) para que não ocorra deterioração dos rolamentos. Nota-se por meio da figura 15 que, com essa abordagem, a corrente de descarga não ultrapassa os $600 \mu \mathrm{A}$ de pico, fato que eleva consideravelmente a vida útil do rolamento. Assim, pode se confirmar que a inserção da capacitância $C d$ é uma abordagem eficiente para evitar falhas prematuras e recorrentes nos rolamentos de motores de indução trifásicos.

Figura 15 - Corrente (vermelho) no rolamento de 6204 2rs e tensão no eixo (verde) com a inserção da capacitância $C_{d}$. $O$ transitório indica uma corrente de descarga

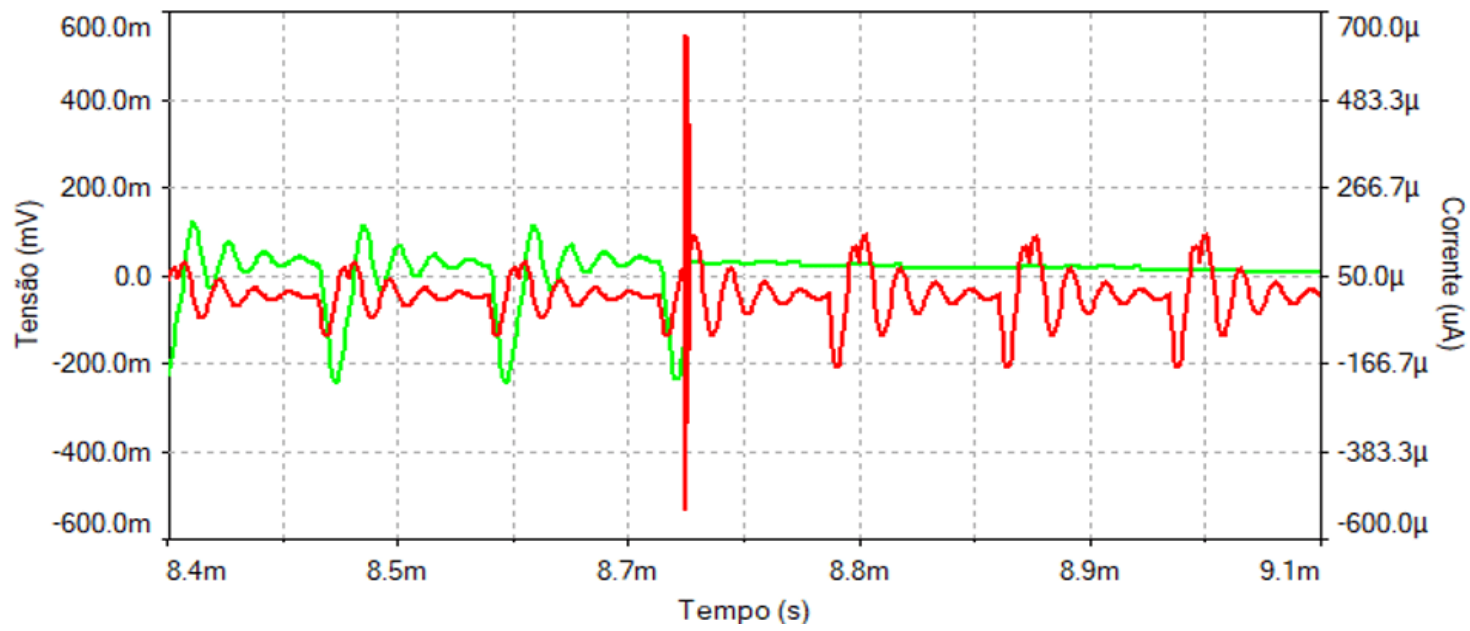

Fonte: Autor.

RC: 68583

Disponível em: https://www.nucleodoconhecimento.com.br/engenharia-eletrica/supressao-decorrente 


\section{CONCLUSÃO}

Visando a redução da tensão entre o eixo e carcaça e assim mitigar a corrente de descarga através dos rolamentos, diversas abordagens foram apresentadas e analisadas. Mais especificamente, a abordagem que propõe a inserção de uma capacitância entre o eixo e o núcleo do rotor, a fim de gerar uma reatância de alto valor e assim reduzir a tensão entre eixo e carcaça, foi avaliada. Um motor BLDC foi empregado para o estudo e seu circuito equivalente em alta frequência foi identificado por meio de equações eletromagnéticas e de medições laboratoriais. Pode-se concluir que tal abordagem apresenta as seguintes contribuições:

- Mitiga a corrente de descarga nos rolamentos de motores BLDC com grande eficiência;

- Contribui de forma direta para o aumento da vida útil dos motores BLDC;

- Dispensa o uso de abordagens que apresentam a necessidade de manutenção periódica como, por exemplo, as escovas no eixo e/ou graxas condutivas nos rolamentos.

Como desvantagem dessa abordagem pode-se citar o aumento de uma etapa no processo de produção do motor.

Agradecimentos: Ao CNPq pelo auxílio financeiro concedido para realização deste trabalho.

\section{REFERÊNCIAS}

$A D A B I J$. et al. "Bearing damage analysis by calculation of capacitive coupling between inner and outer races of a ball bearing," apresentado em Conf. Power Electronics and Motion Control, p. 903-907, set. 2008.

ARAÚJO, R. S.. Desgaste Prematuro e Falhas Recorrentes em Rolamentos de Motores de Indução Alimentados por Inversores: Análise e Proposta de Solução. 2011. 141f. Dissertação (Mestrado) - Universidade Federal de Minas Gerais, 
Programa de Pós-Graduação em Engenharia Elétrica, Belo Horizonte. Disponível em: $<$ https://repositorio.ufmg.br/bitstream/1843/HPAA8NTQXG/1/dissertacao_romero_1_.pdf>. Acesso em: 02 set. 2020.

BINDER, A.; MUETZE, A. Scaling effects of inverter-induced bearing currents in AC machines. IEEE Transactions on industry applications, v. 44, n. 3, p. 769-776, Mai/Jun. 2008. Disponível em: < https://ieeexplore.ieee.org/document/4270866>. Acesso em: 5 jun. 2020.

BUSSE, Doyle et al. Bearing Currents and Their Relationship to PWM Drives. IEEE TRANSACTIONS ON POWER ELECTRONICS, v. 12, n. 2, Mar. 1997. Disponível em: $<$ https://ieeexplore.ieee.org/document/558735>. Acesso em: 13 out. 2020.

JOUANNE, Annette Von; ZHANG, Haoran. "A Dual-Bridge Inverter Approach to Eliminating Common-Mode Voltage and Bearing and Leakage Currents", IEEE Trans on Power Electronics, v. 14, n. 1, p. 43-48, Jan. 1999. Disponível em: < https://ieeexplore.ieee.org/stamp/stamp.jsp?arnumber=737591>. Acesso em: 08 Out. 2020.

KERKMAN, R.; SKIBINSKI, G.; SCHLEGEL, D. . Unintended consequence of low rise time IGBTs, In: The International Electric Machines and Drives Conf. (IEMDC), Madison, WI, Jun. 2003.

KIM, Kyung Tae; Hur, Jin. Reduction of shaft voltage by the flux-path design in IPM-type BLDC motor, 2013 International Conference on Electrical Machines and Systems (ICEMS), Busan, p. 803-806, Oct.2013. Disponível em: < https://ieeexplore.ieee.org/document/6713158>. Acesso em: 22 de Out. 2020.

LINK, P. J. . Minimizing electric bearing currents in ASD systems, IEEE Ind. Appl. Mag., v. 5, n. 4, p. 55-66, Jul./Aug. 1999. Disponível em: < https://ieeexplore.ieee.org/stamp/stamp.jsp?tp=\&arnumber=771367>. Acesso em 02 de ago 2020. 
MAETANI, T. et al. Comparing brushless dc motors, IEEE Trans. Ind. Appl., v. 21, n. 6, p. 29-35, Nov/dez. 2015.

MAETANI, T. et al. "Approaches to suppressing shaft voltage in brushless DC motor driven by PWM inverter," apresentado em 2011 Int. Conf. Eleger. Mach. Syst. (ICEMS), p. 1-6, ago. 2011.

MUETZE, Annette; BINDER, Andreas. Don't lose your bearings-Mitigation techniques for bearing currents in inverter-supplied drive systems, IEEE Ind. Appl. Mag., v. 12, n. 4, p. 22-31, Jul./Aug. 2006.

MUETZE, Annette; BIDER, Andreas. Calculation of Circulating Bearing Currents in Machines of Inverter-Based Drive Systems, IEEE Trans. Ind. Electron., v. 54, n. 2, p. 932-938, Apr. 2007. Disponível em: < https://ieeexplore.ieee.org/document/4135424>. Acesso em: 8 abr. 2020.

RIEHL, Rudolf Ribeiro; RUPPERT, Ernesto. "Método experimental para determinação das capacitâncias parasitas do motor de indução trifásico acionado por inversor mpl", Revista Controle \& Aplicação,v. 23, n.2, p. 153-163, 2012.

SIEMENS A\&D SD CS SERVICE COOPERATION. "Informações gerais de serviço para motores padrão de baixa tensão". Technical report. 2006.

WILLIAM, H. Oh; WILLWERTH, Adam. "Shaft grounding- A solution to motor bearing currents, Refrigerating and Air-Conditioning Engineers, Inc. Published in ASHRAE Transactions, v. 114, n. 2, 2008.

Enviado: Novembro, 2020.

Aprovado: Dezembro, 2020. 